\title{
Reportes consulares e historiografía del fenómeno cristero
}

\author{
Servando Ortoll* \\ UNIVERSIDAD DE COLIMA
}

\begin{abstract}
Visión crítica de las fuentes y presupuestos analíticos de las principales interpretaciones de la guerra cristera.
\end{abstract}

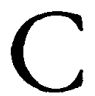
ientíficos sociales, como Leon Festinger y Daniel Katz, han resaltado desde hace mucho tiempo la importancia que tienen los reportes emitidos por los agentes diplomáticos extranjeros sobre las condiciones reinantes en los países huéspedes. La Característica de los agentes consulares,

* Agradezco los comentarios y críticas a una versiónanterior de este ensayo, enorden alfabético, a Sigmund Diamond, Stephen Haber, Jean Meyer, José Ortiz Monasterio, Herbert Passin, Annette B. Ramírez de Arellano, Pablo Serrano Álvarez, Robert Wasserstrom y Viviana Zelizer. Debo a Rubén Carrillo la revisión de estilo. Con leves modificaciones y con una introducción distinta, este escrito fue tomado de Ortoll, "Catholic", 1987, pp. 7-29. La investigación para este escrito fue a poyada en parte por la Universidad de Colima. según Festinger y Katz, es la de conocer a fondo situaciones ignoradas por el ciudadano promedio. Aquéllos, exponen los mismos autores, poseen los medios (y las facilidades) de ponerse en contacto con las autoridades del lugar, no sólo políticas, sino también militares.

La facilidad con la que estos agentes consulares logran obtener información de primera mano, condujo a que muchos historiadores la consideraran como fuente de autoridad irrefutable. Esto precisamente le ha ocurrido a gran parte de los estudiosos del fenómeno cristero. Muchos de ellos convirtieron algunos reportes consulares producidos al tiempo (e inmediatamente después) del movimiento cristero, en esas "autoridades" de 
las que R. G. Collingwood aconseja retirarse. "Hay un tipo de historia que depende enteramente del testimonio de autoridades", nos dice Collingwood:

El método por el cual se procede consiste en decidir, primero, sobre qué queremos saber $y$, luego, ir en busca de afirmaciones sobre ello, orales o escritas, que pretendan haber sido hechas por actores de los acontecimientos de que se trate, o por testigos de los mismos, o por personas que repiten lo que les han dicho actores y testigos a sus informantes, o a los que informaron a sus informantes, etc. Habiendo encontrado en tales afirmaciones algo que casa con su propósito, el historiador lo entresaca e incorpora a su propia historia, traducido, si es necesario, y vuelto a vaciar en lo que considera estilo apropiado. ${ }^{1}$

El problema fundamental del historiador a que se refiere Collingwood, es que acepta sin crítica alguna los testimonios de autoridades diferentes, entresacándolos y combinándolos, hasta llegar a la conformación de un relato, en donde la postura del historiador se pierde en el trasfondo. ${ }^{2}$ Cómo este tipo de historia, pese a las mejores intenciones de algunos, permanece vivo dentro de la historiografía del fenómeno cristero, es el punto que pretendo discutir y documentar en el presente ensayo.

Comenzaré diciendo que, para propósitos prácticos, la mayoría de los escri-. tos realizados sobre el movimiento cristero-derivados de los escritos de observadores consulares contemporáneos- cubren dos temas importantes y ofrecen explicaciones diferentes, ya sea para el inicio o término del conflicto armado. Un grupo de estudiosos se enfoca a las divisiones políticas o ideológicas

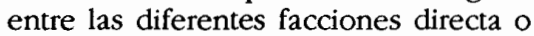

\footnotetext{
${ }^{1}$ Collingwood, Idea, 1984, p. 249.

${ }^{2}$ Ibid., pp. 249-250.
}

indirectamente involucradas en el movimiento, mientras que otro enfatiza el papel del embajador norteamericano como el elemento más importante en detener su marcha. ${ }^{3}$

Desde este punto de vista, dos reportes y un ensayo producidos por tres agentes consulares, son muy pertinentes. El primero es un memorándum escrito por el encargado de negocios francés en México, Ernest Lagarde; el segundo fue escrito por George Rublee, asistente personal del embajador norteamericano en México; y, finalmente, el ensayo es obra de Miguel Cruchaga Tocornal, ex embajador chileno en México. Estos tres documentos fueron particularmente importantes al influir sobre investigaciones hechas más tarde, en torno al fenómeno cristero. Dado que los escritos de los tres agentes consulares influyeron, al menos, sobre dos escuelas que analizan los motivos por los cuales se inició el conflicto o fue resuelto años más tarde, los analizaré por separado en este ensayo.

\section{la postura de lagarde y Cruchaga}

La mayoría de los historiadores que se concentran en las posturas divergentes de quienes estuvieron involucrados en el movimiento cristero, no se ponen de acuerdo sobre qué facciones se encontraban divididas alrededor de cuáles asuntos.

Quizá el reporte de más influencia sobre las razones para el estallido del movimiento cristero, fue el escrito por

${ }^{3}$ Un tercer grupo acusa al obispo Pascual Díaz por el fracaso del movimiento. Esta es la versión sostenida por la mayoría de los líderes de la Liga, en particular por Miguel Palomar y Vizcarra. Esta literatura fue principalmente producida por participantes activos en el conflicto y no por historiadores. Por esta razón, no ha sido incluida en esta reseña historiográfica. 
Lagarde. El encargado de asuntos de la embajada francesa escribió su reporte el 18 de septiembre de 1926, inmediatamente después de que se cerraran las puertas de las iglesias al culto católico en todo México, siguiendo las órdenes de los obispos, como medida de protesta, en contra de la aprobación legislativa que ellos calificaban de antirreligiosa. Como sabemos, ésta fue una de las razones que llevaron a grupos de campesinos católicos a rebelarse contra el gobierno del presidente Plutarco Elías Calles, en varios estados del occidente mexicano.

Católico y observador cercano del creciente conflicto entre la Iglesia y el Estado, Lagarde sugirió que había varias posturas relacionadas con el estallido del conflicto. En su reporte, insistió en que el Vaticano quería paz, mientras que los obispos mexicanos -a quienes acusó de "intransigentes" y "combativos", y de comportarse "insubordinada" y "beligerantemente"estaban resueltos a llegar a la violencia:

El Vaticano deseaba con fuerza la pacificación [...] se inclinaba hacia una política de transigencia, por un acuerdo tácito, que hubiera dejado sin cambiar los puntos [de la Constitución de 1917] contra los cuales se había objetado, pero que hubiera permitido relegarlos al campo de la teoría, de forma tal que no fueran realmente aplicados. ${ }^{4}$

Escribiendo enmedio de la conflagración armada, el encargado de asuntos francés explicó:

El Vaticano deploró que el clero mexicano, unido y combativo, en vez de tratar de llegar a un arreglo amistoso con las auto-

4 Ernest Lagarde a Aristide Briand, 18 de septiembre de 1926, Correspondencia diplomática francesa, 1924-1928, Quay D'Orsay, París. Referencia en Meyer, Cristiada, 1974, vol. 1, p. 393. ridades [gubernamentales], mantenga una actitud de hostilidad abierta e insista en no tener relaciones con el gobierno $[\ldots]^{5}$

Pero si al inicio de su reporte Lagarde acusó a todos los obispos de estar comprometidos con la violencia, páginas más adelante reconoció que los prelados no se habían puesto de acuerdo respecto a qué postura debía tomar la Iglesia frente al Estado:

El obispo de Huejutla se embarcó en un duelo abierto contra la ley y el gobierno, predicando rebelión; otros, como el arzobispo de Monterrey, invitaron a los fieles a la resistencia pasiva; otros más [...] tomaron una posición cunsitucionalista, exigiendo vigorosamente el respeto por los derechos cívicos y las garantías otorgadas a todos por la ley fundamental, y tratando de obtener del poder público una ley honorable para la Iglesia. ${ }^{6}$

En suma, Lagarde veía la postura del Vaticano como dependiente de las decisiones tomadas por los obispos mexicanos, quienes, según él, debían ser responsabilizados por lo que sucediera dentro del conflicto Iglesia-Estado. El bien informado Lagarde, sin embargo, no permaneció por mucho tiempo en México. Fuellamado a Francia, antes de que pudiera presenciar cómo se desarrollaron los asuntos religiosos en México, de los que habló en su extenso reporte. Esto, sin embargo, no impidió que su escrito fuera de lo más influyente en la interpretación de los eventos que habrían de sucederse en los años siguientes (así como en su historiografia): la embajada norteamericana en la ciudad de México recibió una copia del memorándum de Lagarde y lo

\footnotetext{
sIbid., vol. 1, p. 15

${ }^{6}$ Ibid.
}

\section{8}

5 
utilizó como una importante fuente de información en los años posteriores.'

Otro observador cercano del movimiento cristero fue el embajador chileno en México, Miguel Cruchaga Tocornal. ${ }^{8} \mathrm{Al}$ igual que Lagarde, Cruchaga vio la movilización cristera comoel resultado de posturas opuestas, respecto al camino que los católicos mexicanos debían tomar frente al gobierno. Pero a diferencia de Lagarde, Cruchaga advirtió que las diferencias se habían producido entre los obispos, que eran transigentes, y los líderes de una organización laica, conocida con el nombre de Liga Nacional Defensora de la Libertad Religiosa, que querían la guerra:

desde que llegué a México pude observar que había serias rivalidades entre los miembros de la Liga y el Comité Episcopal, especialmente entre aquéllos y los obispos [Leopoldo] Ruiz [y Flores] y [Pascual] Díaz [y Barreto]. Estas rivalidades provenían de un diverso criterio para apreciar cuál era el mejor camino para alcanzar el triunfo de los derechos de la Iglesia. La Liga quería procedimientos enérgicos que llegaran hasta la lucha por las armas, y los obispos no aceptaban el alzamiento en armas, y optaban por gestiones, si bien enérgicas, realizadas dentro de un plano conciliador. ${ }^{9}$

Viendo a la Iglesia como monolito, y a Díaz como representante del consenso de los obispos sobre el asunto, Cruchaga

${ }^{7} \mathrm{El}$ memorándum Lagarde sirvió de gran apoyo para el desarrollo del escrito de George Rublee, analizado más adelante: "The religious conflict in Mexico and its adjustment", reporte confidencial mimeografiado, México, Embajada norteamericana, septiembre de 1930. National Archives (NA) Record Group (RG) 59, State Department Records (SDR): 812.404/1040.

${ }^{8} \mathrm{~A}$ diferencia de los escritos de Lagarde y de Rublee, el de Cruchaga Tocornal está basado en sus memorias y fue publicado años después de que el embajador dejara su puesto diplomático en México. Véase, Cruchaga, "Conflicto", 1949, pp. 212-255.

${ }^{9}$ Ibid., pp. 225-226.
Tocornal escribió que Díaz (implicando su actuación como portavoz de todos los obispos) "nunca estuvo de acuerdo con [la Ligal cuando entró por el camino de la lucha armada, por encontrar esta lucha contraria a los principios de la Iglesia católica". ${ }^{10}$ A diferencia de Lagarde, por lo tanto, Cruchaga vio las divisiones sobre políticas a seguir, como emanadas del conflicto entre los obispos -unidos sobre este punto-y los miembros de la Liga.

\section{La postura de Meyer}

Varios estudiosos siguieron la postura de Lagarde en principios, mientras que otros estuvieron de acuerdo -a sabiendas o sin saberlo- con la postura de Cruchaga. Un tercer grupo combinó ambas posturas dentro de un todo "coherente". Este último grupo está representado principalmente por el trabajo del historiador francés Jean Meyer. ${ }^{11}$ Después de que su tesis doctoral, defendida en la Universidad de París, se tradujera al español, fue considerada por eruditos y por la prensa en general, como el "estudio definitivo" de la cristiada ${ }^{12}$ y su popularidad puede ser parcialmente explicada por el aparente uso juicioso de las técnicas de investigación. ${ }^{13}$

En la versión inglesa de su libro sobre la

${ }^{10}$ Ibid., p. 227.

"Para dos visiones diametralmente opuestas sobre el rigor metodológico y el enfoque teórico de Meyer, véanse Mabry, "Mexican", 1978, pp. 86-90, y Jrade, "Counterrevolution", 1980, pp. 19-30. Esta discusión del trabajo de Meyer sobre la rebelión cristera, se limita a la versión inglesa de su tesis doctoral. Véase Meyer, Cristero, 1976.

${ }^{12}$ Mabry, "Mexican", 1978, p. 86; Jrade, "Counterrevolution", 1980, p. 21.

${ }^{13}$ En su tesis doctoral, Jrade analiza con gran detalle lo que él ve como las deficiencias metodológicas de Meyer y concluye que su confiabilidad es más aparente que real. Jrade, $o p$. cit., p. 22. 


\section{SECUENCIA}

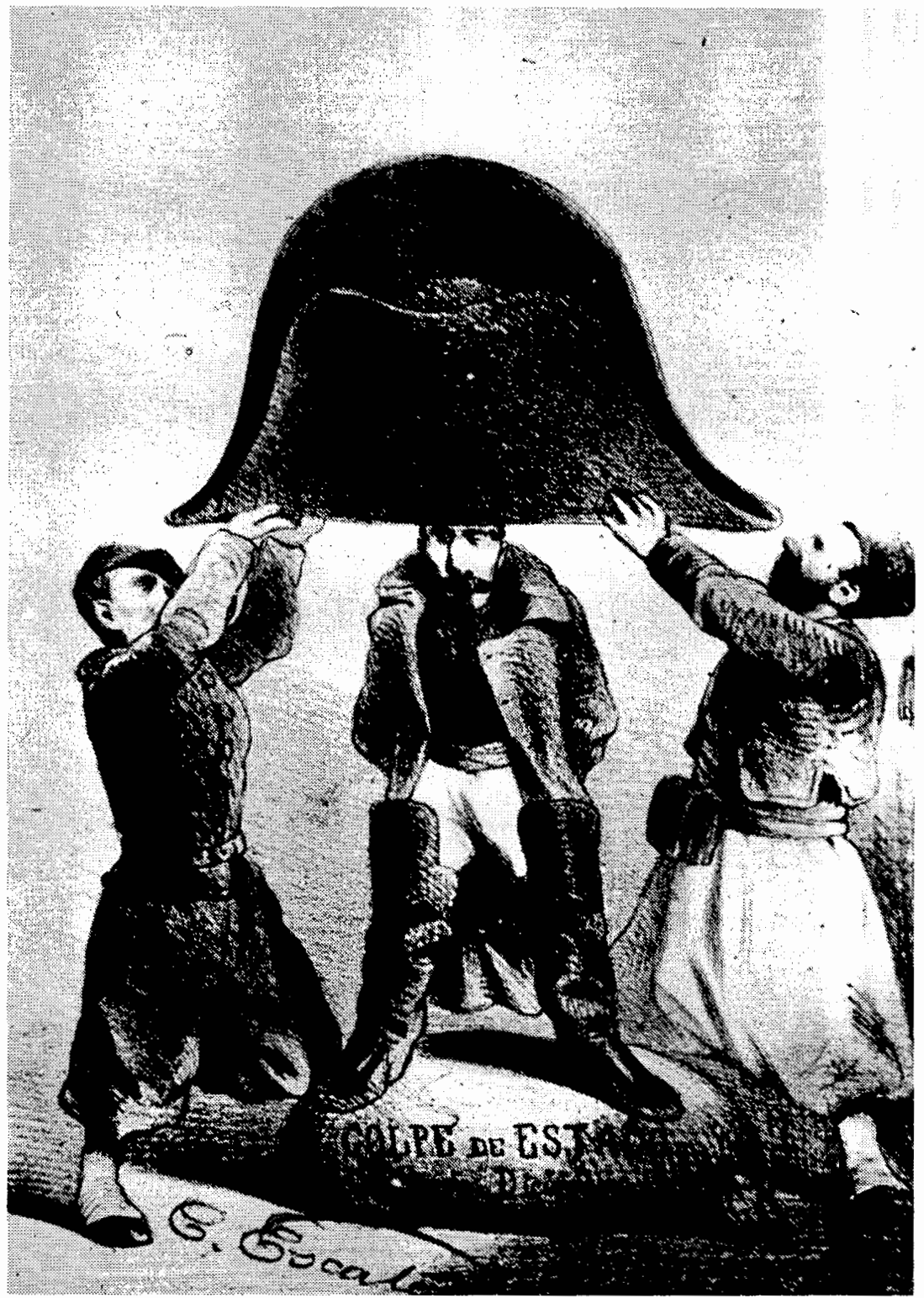


movilización cristera, Meyer sugiere que el Vaticano favoreció el acomodamiento y no "compartió las actitudes combativas de un sector del clero mexicano" que no quiso transigir con el gobierno. Él afirma que "Roma le otorgó más crédito al gobierno mexicano que a los obispos":

Roma persistió en su actitud moderada, y hasta el último momento buscó un "compromiso de facto", por el cual continuaría esperanzada durante los tres años que duró la guerra, y que se impuso sobre los católicos mexicanos en junio de $1929 .{ }^{14}$

Meyer ve, por lo tanto, la división política más grande como resultado de la oposición del Vaticano contra los obispos mexicanos. Argumenta que el Vaticano quería llegar a un acuerdo con el gobierno mexicanoen forma pacífica, e hizo todo lo que pudo (siguiendo una línea política muy definida) por llegar a tal acuerdo. La postura de Meyer soslaya el hecho de que el Vaticano no fue consistente en su actitud hacia el gobierno mexicano durante los años que duró la cristiada. Ahora sabemos que, desconociendo en detalle la situación mexicana, el Vaticano dio igualdad de confianza a las dos facciones que promovian caminos divergentes, para solucionar el conflicto Iglesia-Estado. ${ }^{15}$

${ }^{14}$ Meyer, Cristero, 1976, p. 39.

15 Para otro análisis de este problema, véase Ortoll, "Faccionarismo", 1985, pp. 27-41. A diferencia de Meyer, quien trata de absolver al Vaticano de toda culpa o participación en el problema político mexicano, esbozo en este ensayo las divisiones entre los mismos obispos, los caminos que ellos sugirieron debían ser seguidos para resolver el problema, y cómo cabildearon en el Vaticano, tratando de que éste favoreciera una solución sobre la otra. En este sentido, mi argumento sigue las líneas analíticas sugeridas por Wilkie, en su artículo "Meaning", 1966, pp. 214-233. En su ensayo, Wilkie sugiere que al contrario de lo que se había creído anteriormente, ni la Iglesia ni el Estado eran monolitos, y había que analizar más profundamente las implicaciones de esta observación.
Otro punto, en donde el análisis de Meyer resulta muy cuestionable, se refiere al papel de los obispos durante el movimiento cristero. Meyer afirma que, al inicio del conflicto, una "mayoría" de los obispos mexicanos favorecía la "tolerancia" ${ }^{16}$ Según él, el Vaticano se opuso al levantamiento, pero no se atrevió a imponer su postura sobre los obispos mexicanos, la mayoría de los cuales favoreció la transigencia, y los responsables por la movilización fueron los líderes de la Liga y una minoría de obispos disidentes: "Los directores de la Liga y sus consejeros jesuitas favorecían la resistencia, pero el episcopado, a pesar de estar convencido de la necesidad de esa resistencia, estaba dividido en cuanto a la acción que debía tomarse". Roma, por otra parte, permanecía "callada, indecisa a imponer un curso de acción sobre los obispos divididos". ${ }^{17}$

Mientras que reconoce la existencia de una división entre los obispos, para Meyer esta discordia no afectó tanto a la movilización, como a la conciliación:

Tomó toda la energía de un político como Calles, para unirlos [a los obispos] en un movimiento de resistencia, mismo que era temporal y nunca sin reservas. Aparte dela gran, vaga mayoría de los indecisos, había seguidores incondicionales de Roma, que esperaban que ésta se pronunciara sobre el asunto [...]; los que apoyaban al Cardenal [Pietro] Gasparri y la conciliación a cualquier precio; y, finalmente, aquellos que podríamos llamar nacionalistas, que no tenían una política claramente definida, pero que estaban convencidos de que gran parte del problema se derivaba de la ignorancia que Roma tenía sobre el país. ${ }^{18}$

Dada la existencia de este grupo de

${ }^{16}$ Meyer, Cristero, 1976, p. 42.

${ }^{17}$ Ibid., p. 43.

${ }^{18} \mathrm{Ibid}$., p. 46. 
obispos indeciso y no comprometido, era obvio-desde la perspectiva de Meyerque los prelados tuvieron poco que ver con la movilización. Fueron los híderes de la Liga quienes acudieron a los obispos, deseosos de legitimar el levantamiento, y recibieron de ellos "una expresión prudente de aceptación", en cuanto a la licitud teológica del movimiento, interpretándola como "apoyo incondicional", para iniciar la lucha:

Fortalecido por el apoyo [de los obispos], el comité directivo de la Liga ordenó un levantamiento general para los primeros días de enero de 1927, demostrando así su inexistencia militar y su irresponsabilidad política. ${ }^{19}$

La Liga, originalmente fundada como organización no violenta, había sido "reducida", de "ser el portavoz del pueblo católico [... ] a una facción de conspiradores que habían engañado a los líderes del movimiento civil de resistencia [...], al llevar a las masas a la matanza". ${ }^{20}$ Meyer claramente acusa a la Liga por el estallido de la movilización:

La Liga, que al principio gozó de las simpatías del episcopado y de Roma, había alienado a todo hombre de buena voluntad hacia finales de 1927, cuando sólo tres prelados se encontraban favorablemente dispuestos hacia ella. ${ }^{21}$

${ }^{19}$ Ibid., p. 51.

${ }^{20}$ Este es otro tema bajo discusión entre estudiantes del movimiento cristero. Acepto como válida la visión presentada por un antiguo dirigente de la Liga, quien afirmó que, tras el cierre de las iglesias en el verano de 1926, la Liga "movilizó su organización para unir movimientos pequeños [que se desataron espontáneamente en varias partes del occidente mexicanol, dentro de una lucha unificada" en contra del gobierno. Testimonio de Miguel Palomar y Vizcarra dado al profesor Wilkie, Véase Wilkie, "Meaning", 1966, p. 225.

${ }^{21}$ Meyer, Cristero, 1976, p. 61.
El análisis de Meyer puede ser resumido como sigue: el Vaticano, y la mayoría de los obispos, estaban a favor de la tolerancia. Sólouna minoría, influenciada por los líderes de la Liga, cayó víctima del extremismo, y confió en sus planes de insurrección. Los líderes de la Liga fueron muy irresponsables y engañaron a todos, incluso a las personas de "buena voluntad", quienes inicialmente los apoyaron por sus tácticas pacíficas. Más tarde, sin embargo, la Liga adoptó tácticas paramilitares, marginándolos a todos; por lo tanto perdió popularidad, y con ella, la posibilidad de que algún día lograra algo positivo. Los "buenos obispos", aquellos que entendían adecuadamente las políticas del Vaticano, trabajaron sin descanso, hasta lograr un acuerdo que concordara las políticas vaticanas, con el Estado mexicano. Parece que no me equivoco al afirmar que la posición ideológica de Meyer nole permite ver cómo las posturas de los obispos cambiaron, según se desarrolló el conflicto.

Al hablar de una "minoría" de obispos que favoreció la movilización, Meyer implica que la mayoría se opuso. En realidad, esto estuvo muy lejos de ser el caso. Si hubo una "minoría", fue la formada por los obispos Ruiz y Díaz, quienes a la larga lograron persuadir a la opinión pública de que su postura era la correcta (con el auxilio de la National Catholic Welfare Conference, organización oficiosa de obispos norteamericanos) y consolidar una estructura de poder, que les permitió derrotar a los obispos que favorecian el levantamiento, y se declaraban en contra de la conciliación. El arguménto de Meyer, por lo tanto, confunde al lector: la minoría de la que habla, no lo era realmente cuando empezó la movilización; más aún, lo que importa no es si una "minoría numérica" favoreció la movilización -como él arguye- o si una 


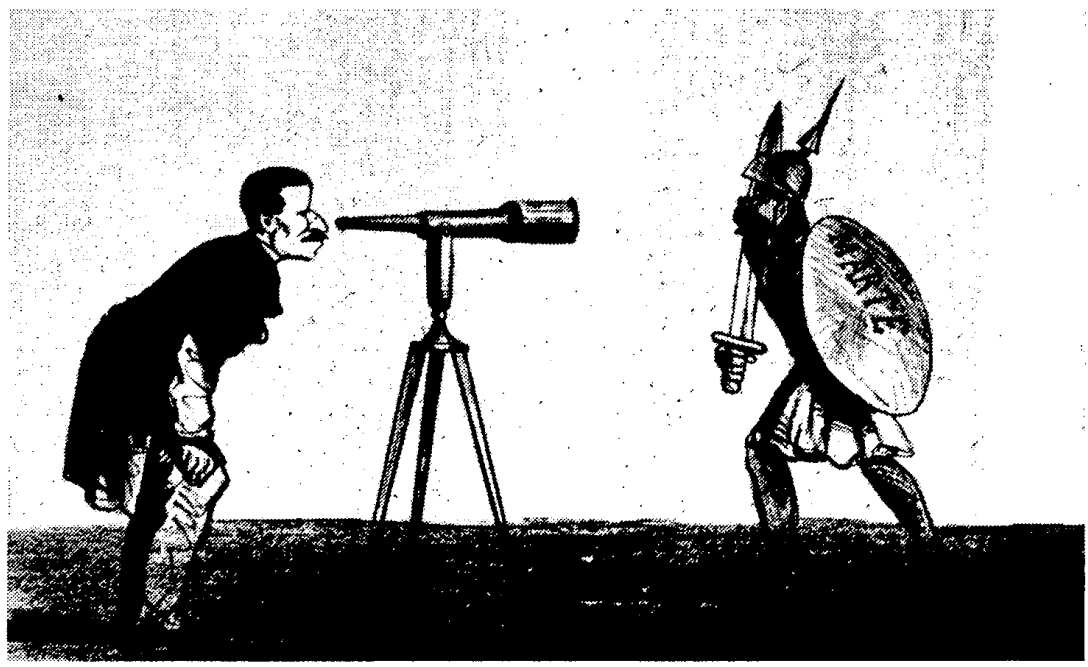

"minoría" se le oponía -como lo he demostrado en otro lugar- sino, más bien, el apoyo político que cualquiera de las dos "minorías" pudo movilizar en defensa de su postura.

\section{LA INTERPRETACIÓN DE BAILEY}

David C. Bailey, en su libro sobre el levantamiento cristero, traza las divisiones entre los obispos como un fenómeno mucho más dinámico que el que presenta Meyer, pero llega a una conclusión inexacta, sobre el porqué los obispos, que originalmente estuvieron del lado de la movilización, más tarde cambiaron de forma de pensar:

Todos los obispos aceptaron la decisión de suspender el culto público y probablemente una mayoría, al principio, favoreció la "defensa armada". Pero, según se desvanecieron las posibilidades de éxito mediante el uso de las armas, también se desvaneció su militancia. Un puñado de ellos apoyó la causa hasta el final; otros la abandonaron; otros trataron de desligarse de la responsabilidad de ésta, a pesar de continuar alentándola en privado. Roma finalmente tomó la dirección de asuntos de la Iglesia mexicana en sus manos, y la regresó a la jerarquía, en parte, sólo en vísperas de los arreglos.

Mientras que el análisis de Bailey es correcto, al señalar los cambios en las posturas políticas de los obispos, se equivoca en cuanto a las razones para tales cambios y sus implicaciones. Ahora sabemos, por ejemplo, que aun aquellos que se opusieron a una reacción extrema, contra las políticas del gobierno, estuvieron de acuerdo, en un principio al menos, con la postura militante de la mayoría de los obispos. Mientras que es difícil probar, si la oportunidad que los cristeros tuvieron de derrocar al régimen de Calles por la fuerza realmente se "desvaneció"; mi análisis -basado en material de archivos no disponible a Bailey- demuestra que la mayoría de los obispos se 
opuso a la conciliación con el gobierno hasta el último momento y que, cuando finalmente capituló, se debió a las intrigas de los obispos Ruiz y Díaz quienes trabajaron conjuntamente, para neutralizar y desmantelar la postura antigobiernista de los obispos militantes.

Las autoridades vaticanas se enfrentaron a un dilema al verse forzadas a decidir en cuál postura confiar, y cómo actuar frente al gobierno mexicano. Bailey, sin embargo, presenta al Vaticano como "dolorosamente" indeciso, respecto a la forma de reunir a los obispos en un solo curso de acción. Pero una vez persuadido de que "los obispos aceptarían [...] un arreglo de factoque cubriera lo esencial", "actuó para terminar el estancamiento a nivel político-eclesiástico, aunque mediante esto arrebató a [la Liga] y a los cristeros toda esperanza de victoria, $y$, de hecho, sofocó la rebelión". ${ }^{22}$

Como Meyer, Bailey trata de absolver a los obispos de su responsabilidad final sobre el fracaso de la movilización y de eximirlos por llegar a un acuerdo con el gobierno. Los documentos a los que tuvo acceso no le permitieron detectar los pasos furtivos que Ruiz y Díaz dieron, para redirigir el curso de la movilización y apoderarse del liderazgo del comité de obispos. Al igual que Meyer, Bailey siguió el reporte de Lagarde muy de cerca, aumentándolo al documentar eventos históricos posteriores, pero aceptando como exacto aquel análisis escrito, como vimos, al inicio del conflicto. ${ }^{23} \mathrm{~A}$ pesar de la diversidad de documentación de archivos, disponible tanto para Meyer como

${ }^{22}$ Bailey, Viva, 1974, p. 306.

${ }^{23}$ En su ensayo bibliográfico, Bailey afirma que el embajador norteamericano Dwight W. Morrow "consideraba a Lagarde como el hombre mejor informado sobre el tema [Iglesia-Estado] en México [...]." Véase Bailey, Viia, 1974, p. 314. para Bailey, sus conclusiones fueron en gran medida modeladas por el estudio de Lagarde.

MORROW: LA VISIÓN OFICIAL

El segundo grupo de historiadores que ve las acciones del embajador norteamericano Dwight W. Morrow, como las más importantes en detener el levantamiento, sufren de un problema más excusable; lo limitado de los materiales de primera mano accesibles a ellos, no les permitió hacer una evaluación más balanceada y ahondar en el papel jugado por otros individuos e instituciones para restaurar la paz en México.

Como en el caso del primer grupo de estudiosos analizado, los escritos de este grupo estuvieron basados, en gran medida, en un memorândum mecanografiado de George Rublee -miembro del staff personal de Morrow en la embajada norteamericana de la ciudad de México-sobre "El conflicto religioso en México y su arreglo", elaborado en septiembre de 1930, bajo la petición de Morrow. ${ }^{24}$ Aparte de reconstruir cronológicamente el curso de eventos, durante la permanencia en México del embajador norteamericano, en relación con el conflicto Iglesia-Estado, este reporte coloca a Morrow en el centro de toda la acción. Influenciados por este reporte consular al menos cuatro historiadores presentan a Morrow como el promotor de mejores relaciones

\footnotetext{
${ }^{24}$ Una copia de este memorándum se encuentra en los papeles personales de Dwight Whitney Morrow (DWM), archivados en la biblioteca de Amherst College Library, Amherst, Mass. Vale recordar aqui, de nueva cuenta, que el reporte de Rubiee se basó, en gran medida, en el memorándum de Lagarde.
} 
mexiconorteamericanas, y como la fuerza dirigente detrás del concordato Iglesia-Estado en México.

\section{LA POSTURA DE OTROS ESTUDIOSOS}

L. Ethan Elis reseña los tres años de la movilización cristera y de la diplomacia internacional tras ella y afirma que los arreglos Iglesia-Estado de 1929 en México fueron el resultado del trabajo de Morrow y que "ni el presidente [norteamericanol ni el secretario de Estado se involucraron" en el asunto. Según Elis, el acuerdo de 1929 "encarnó los resultados de un largo y lento proceso en el cual el embajador armonizó [...] dos intereses arrogantes y conflictivos". ${ }^{25}$ Después de "18 meses de negociaciones intermitentes", Morrow logró

llevar a la Iglesia a una posición donde -moderando sus demandas [... - podría restablecer el culto, resignándose a posponer a un tiempo más conveniente la resolución de cuestiones constitucionales y legales, a lo que ningún ejecutivo revolucionario podría comprometerse en ese [preciso] momento.

Según Elis, Morrow fue un diplomático profesional de primera: pudo llevar las dos facciones opuestas a la mesa de negociaciones "con buenos deseos y aplomo, raramente sucumbiendo al desaliento, haciendo borradores de documentos en forma imparcial, para ambos lados", minimizando gradualmente sus diferencias, logrando así llevar a las dos facciones a un acuerdo. ${ }^{26}$

Stanley Ross -quien también basó su trabajo en el memorándum de Rubleellega a conclusiones similares respecto al

25 Elis, "Morrow", 1958, p. 504.

${ }^{26}$ Ibid., p. 505. papel desempenaado por Morrow durante el conflicto:

La finalidad de Morrow fue la de suplantar la desconfianza, por confianza en ambos lados. Tuvo que convencer al clero de que la restauración de su privilegio histórico era imposible y que, si ellos podían aceptar la revolución como un hecho, la Iglesia recobraría sus libertades esenciales y podría proceder a su misión espiritual. El gobierno tuvo que ser convencido de que el clero había aceptado esto y que se desligaria de contrarrevoluciones e intervenciones extranjeras. Para evitar la continuación de la controversia, la Iglesia tendría que acomodarse a las leyes que el gobierno aplicaría con espíritu de moderación. ${ }^{27}$

Según Ross, la clave del "éxito" de Morrow fue su personalidad, y su actitud amistosa hacia el gobierno mexicano. En su nombre, y en el de mejores relaciones México-Estados Unidos, había intervenido para arreglar la disputa:

Al limpiar la atmósfera de desconfianza y de temor y al restaurar las relaciones mexicanas-norteamericanas a un camino pacifico, Dwight Morrow ayudó a fortalecer el gobierno mexicano y a asegurar su supervivencia. Motivado por un deseo de ver a México como vecino pacífico y próspero, Morrow se interesó en todo aquello que afectaba la estabilidad y el progreso del país. Siempre que surgía un problema militar, político o económico, se le encontraba apoyando al régimen establecido $y$ deseando colocar en la balanza el prestigio de su posición en su favor ${ }^{28}$

En otro sitio escribió Ross:

Morrow ofreció sus buenas, aunque extraoficiales conexiones, para mediar la con-

${ }^{27}$ Ross, "Dwight", 1958, pp. 506-528.

${ }^{28}$ Ibid., p. 527. 
troversia, no sólo porque le entristecían las dificultades del pueblo mexicano, al cual se le había negado el consuelo de su religión sino también por las convicciones de que gobierno ordenado, crédito restaurado y progreso económico, estaban amenazados por el problema. ${ }^{29}$

Una postura similar la refleja Elizabeth Ann Rice, quien subraya la capacidad personal de Morrow para lograr una reconciliación entre la Iglesia y el Estado: "La personalidad cálida del embajador, su capacidad de comprender la postura de un opository su respeto por Calles [...] le ganaron la estima personal del ejecutivo mexicano." 30

Consciente del problema Iglesia-Estado, insiste Rice, "Morrow [...] presentó con efectividad una visión relativamente objetiva a Calles y a los representantes de la iglesia católica":

La convicción de Morrow, de que la solución a cualquier problema estaba subordinada al restablecimiento de los oficios religiosos en ese país, le hizo trabajar sin descanso hacia este fin, ignorandola siempre presente crítica católica sobre sus relaciones amistosas con el presidente Calles, y de fuentes opuestas, sobre su asociación cercana con miembros del clero católico [norteamericano]. ${ }^{31}$

Edward J. Berbusse, después de un largo estudio sobre la "crisis religiosa" en México, concluyó lo mismo que los anteriores, que Morrow estaba "consciente" de los "prejuicios religiosos" de Calles. "Aun así", escribió Berbusse, "por su propia naturaleza, Morrow pudo asumir el papel del 'perdonador gentil', y hacer de la amistad personal un instrumento para

${ }^{29}$ Ross, "Ambassador", 1958, p. 285.

${ }^{30}$ Rice, Diplomatic, 1959 , p. 191.

${ }^{31}$ Ibid., pp. 193-194. el cese-al-fuego temporal, en las relaciones Iglesia-Estado".32

Como podemos observar, los cuatro autores anteriores dependen, en gran medida, del reporte consular escrito para el ex embajador norteamericano y, claramente atribuyen a sus esfuerzos personales el término de la movilizaciốn. Dada su imposibilidad de obtener acceso a los archivos de la National Catholic Welfare Conference, por ejemplo, les fue imposible reconstruir los trabajos y esfuerzos de John J. Burke, para solucionar el conflicto. En suma, los autores discutidos arriba, escribieron y reescribieron la versión oficial norteamericana, de lo que sucedió en las negociaciones Iglesia-Estado, convirtiéndose en aquel tipo de historiadores que dependen en gran medida de los testimonios de "autoridades", de los que nos habla Collingwood.

El reporte de Rublee, a semejanza del elaborado por Lagarde, logró colarse en el trabajo de cuatro historiadores que puede ser caracterizado como versiones revisadas ( $\mathrm{y}$ anotadas) del informe original de Rublee. Como en el caso de Meyer y Bailey, estos cuatro historiadores, al depender primordialmente de una sola "autoridad", han terminado por entresacar e incorporar toda la información que consideran pertinente, a su propia interpretación del conflicto cristero, vaciando luego esa información en donde consideran que mejor queda insertada.

\section{UNA REFLEXIÓN FINAL}

Sin intentar menospreciar el papel desempeñado por Morrow en su deseo por lograr el triunfo de las negociaciones Iglesia-Estado, subrayo en otro sitio que, así como su actitud y esfuerzos fueron

\footnotetext{
${ }^{32}$ Berbusse, "Unofficial", 1966, p. 61.
} 
importantes, no habrían sido tanto si los Caballeros de Colón norteamericanos no hubieran logrado colocar el problema religioso en la agenda política de su presidente, y si la NCWC no hubiera utilizado esta situación para ahondar en los planes políticos de éste e influir para que dirigiera su diplomacia hacia México, en los términos que mejor convenían a la Iglesia católica universal. Quiero finalizar diciendo que las diferentes conclusiones a las que he llegado, en mis investigaciones sobre el fenómeno cristero, no son sólo el resultado del trabajo en archivos que no habían sido explorados, sino del esfuerzo consciente para no caer en el repeticionismo ni en el "collage historiográfico", en el que han resbalado muchos estudiosos del tema, al dar a los reportes consulares una autoridad excesiva, que noresiste la crítica historiográfica $y$ documental.

\section{BIBLIOGRAFÍA}

-Bailey, David C., jViva Cristo Rey! The cristero rebellion and the Church-State conflict in Mexico, University of Texas Press, Austin, 1974.

-Berbusse, Edward J., "The unofficial intervention of the United States in Mexico's religious crisis, 1926-1930", The Americas, vol. xxIII, núm. 1, julio de 1966, pp. 28-62.

-Collingwood, Robin George, Idea de la Historia, FCE, México, 1984.

-Cruchaga, Miguel, "El conflicto religioso mexicano", Revista Cbilena de Historia y Geografia, vol. CXIII, 1949, pp. 212-255.

-Elis, L., Ethan, "Dwight Morrow and the Church-State controverse in Mexico", Hispanic
Historical Review, vol. XxxvIII, núm. 4, noviembre de 1958, pp. 482-505.

-Jrade, Ramón, "Counterrevolution in Mexico: The cristeromovement in sociological and historical perspective", tesis doctoral, Brown University, 1980.

-Mabry, Donald J., "Mexican anticlerics, bishops, cristeras, and the devout during the 1920s: A scholarly debate", Journal of Church and State, vol. xx, 1978, pp. 81-92.

-Meyer, Jean, The cristero rebellion: the mexican people between Church and State, 1926-1929, Cambridge University Press, Cambridge, 1976.

La Cristiada, 1973-1974, Siglo

XXI Editores, México, 3 vols.

-Ortoll, Servando, "Catholic organizations in Mexico's national politics and international diplomacy, 1926-1942", tesis doctoral, inédita, Columbia University, Nueva York, 1987. "Faccionarismo episcopal en México y revolución cristera", en Charles A. Reilly y Martín de la Rosa (comps.), Religión y politica en México, Siglo XXI Editores, México, 1985, pp. 27-41.

-Rice, Elizabeth Ann, The diplomatic relations between the United States and Mexico, as affected by the strugglefor religious liberty in Mexico, 1925-1929, Catholic University of America Press, Washington, 1959.

-Ross, Stanley R., "Dwight Morrow ambassador to Mexico", The Americas, vol. XIV, núm. 3, enero de 1958, pp. 272-290. "Dwight Morrow and the mexican revolution", Hispanic American Historical Review, vol. XxxviII, núm. 4, noviembre de 1958, pp. 506-528.

-Wikie, James W., "The meaning of the cristero religious war against the mexican revolution", Joumal of Church and State, vol. viII, núm. 2, 1966, pp. 214-233. 